\title{
Amorphous $\mathrm{ZnO}_{x} \mathrm{~N}_{y}$ thin films with high electron Hall mobility exceeding $200 \mathrm{~cm}^{2} \mathrm{~V}^{-1}$ $\mathrm{s}^{-1}$
}

Takanori Yamazaki, Kei Shigematsu, Yasushi Hirose, Shoichiro Nakao, Isao Harayama, Daiichiro Sekiba, and Tetsuya Hasegawa

Citation: Appl. Phys. Lett. 109, 262101 (2016); doi: 10.1063/1.4973203

View online: http://dx.doi.org/10.1063/1.4973203

View Table of Contents: http://aip.scitation.org/toc/apl/109/26

Published by the American Institute of Physics

\section{Articles you may be interested in}

High mobility $\mathrm{BaSnO} 3$ films and field effect transistors on non-perovskite MgO substrate Appl. Phys. Lett. 109, 262102262102 (2016); 10.1063/1.4973205

Hybrid complementary circuits based on $\mathrm{p}$-channel organic and $\mathrm{n}$-channel metal oxide transistors with balanced carrier mobilities of up to $10 \mathrm{~cm} 2 / \mathrm{Vs}$

Appl. Phys. Lett. 109, 263301263301 (2016); 10.1063/1.4972988

Densification of a-IGZO with low-temperature annealing for flexible electronics applications Appl. Phys. Lett. 110, 011903011903 (2017); 10.1063/1.4973629

High-performance PbS quantum dot vertical field-effect phototransistor using graphene as a transparent electrode

Appl. Phys. Lett. 109, 263101263101 (2016); 10.1063/1.4972984

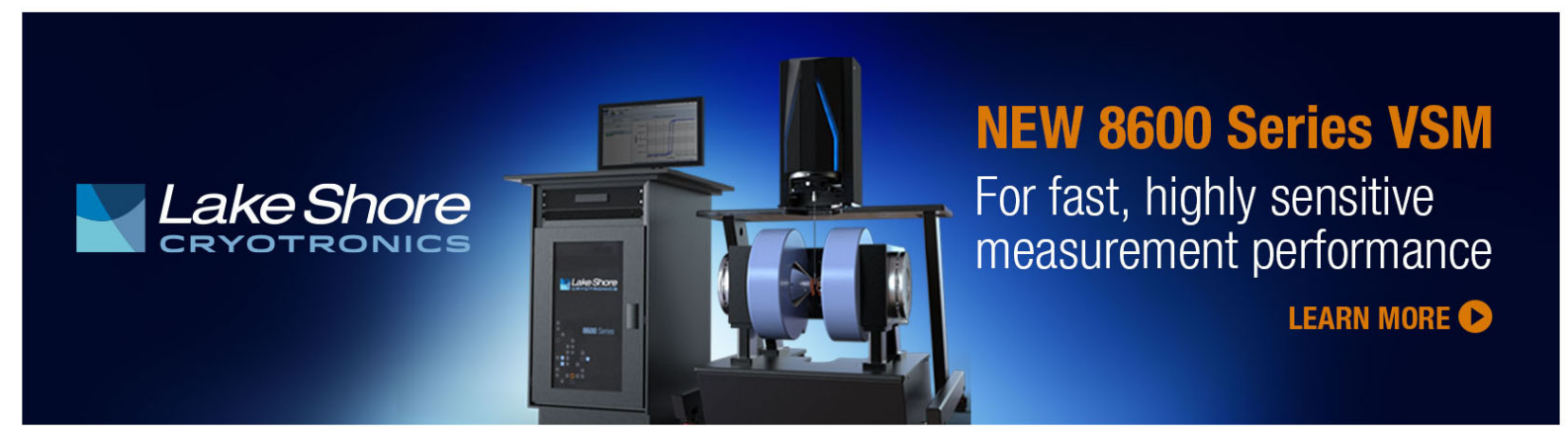




\title{
Amorphous $\mathrm{ZnO}_{x} \mathrm{~N}_{\mathrm{y}}$ thin films with high electron Hall mobility exceeding $200 \mathrm{~cm}^{2} \mathrm{~V}^{-1} \mathrm{~s}^{-1}$
}

\author{
Takanori Yamazaki, ${ }^{1}$ Kei Shigematsu, ${ }^{2}$ Yasushi Hirose,,${ }^{1,2, a)}$ Shoichiro Nakao, ${ }^{2}$ \\ Isao Harayama, ${ }^{3}$ Daiichiro Sekiba, ${ }^{3,4}$ and Tetsuya Hasegawa ${ }^{1,2}$ \\ ${ }^{1}$ Department of Chemistry, School of Science, The University of Tokyo, Bunkyo, Tokyo 113-0033, Japan \\ ${ }^{2}$ Kanagawa Academy of Science and Technology (KAST), Kawasaki, Kanagawa 213-0012, Japan \\ ${ }^{3}$ Graduate School of Pure and Applied Sciences, University of Tsukuba, 1-1-1 Tennoudai, Tsukuba, \\ Ibaraki 305-8573, Japan \\ ${ }^{4}$ University of Tsukuba Tandem Accelerator Complex (UTTAC), 1-1-1 Tennoudai, Tsukuba, Ibaraki 305-8577, \\ Japan
}

(Received 2 October 2016; accepted 13 December 2016; published online 27 December 2016)

\begin{abstract}
Zinc oxynitride $\left(\mathrm{ZnO}_{x} \mathrm{~N}_{y}\right)$ has attracted much attention as an amorphous semiconductor with high electron mobility. Recent studies reported that $\mathrm{ZnO}_{x} \mathrm{~N}_{y}$ thin films grown by sputtering contained nanocrystals, which might reduce their electron mobility through grain boundary scattering. In this study, we fabricated amorphous $\mathrm{ZnO}_{x} \mathrm{~N}_{y}$ thin films on a glass substrate by a less-energetic nitrogen-plasma-assisted pulsed laser deposition (PLD) to suppress the formation of the nanocrystals. Grown by PLD under optimized conditions, these $\mathrm{ZnO}_{x} \mathrm{~N}_{y}$ thin films exhibited extremely flat surfaces with a root-mean-squared roughness $\left(R_{\mathrm{rms}}\right)$ of less than $0.3 \mathrm{~nm}$. The Hall mobility of these films exceeded $200 \mathrm{~cm}^{2} \mathrm{~V}^{-1} \mathrm{~s}^{-1}$ at a critical carrier concentration of $\sim 1 \times 10^{19} \mathrm{~cm}^{-3}$, which was twice as high as the reported values for sputter-deposited films. Meanwhile, the mobility of films with larger $R_{\text {rms }}$ was limited to $\sim 160 \mathrm{~cm}^{2} \mathrm{~V}^{-1} \mathrm{~s}^{-1}$ even at the critical carrier concentration and comparable with that of the sputter-deposited $\mathrm{ZnO}_{x} \mathrm{~N}_{y}$ films. The substantial enhancement in mobility in extremely flat $\mathrm{ZnO}_{x} \mathrm{~N}_{y}$ films demonstrated that suppressing the formation of nanocrystals is the key to fabricating amorphous $\mathrm{ZnO}_{x} \mathrm{~N}_{y}$ thin films with very high mobility. Published by AIP Publishing. [http://dx.doi.org/10.1063/1.4973203]
\end{abstract}

In the last decade, amorphous oxide semiconductors (AOSs) have been extensively studied because of their high electron mobility of over $10 \mathrm{~cm}^{2} \mathrm{~V}^{-1} \mathrm{~s}^{-1}$, which is one order of magnitude higher than those of the amorphous Si:H. ${ }^{1,2}$ Conventionally, AOSs are alloys of two or more metal oxides with different crystal structures where the metal has an electron configuration of $n s^{0}(n-1) d^{10}(n \geq 4)$, such as $\mathrm{ZnO}$ (wurtzite), $\mathrm{Ga}_{2} \mathrm{O}_{3}\left(\beta-\mathrm{Ga}_{2} \mathrm{O}_{3}\right), \mathrm{In}_{2} \mathrm{O}_{3}$ (bixbyite), and $\mathrm{SnO}_{2}$ (rutile). Because the conduction band minima (CBM) in these oxides consist of spatially spread and isotropic metal $s$-orbitals, electron transfer in AOSs is robust against structural distortion, allowing for a high electron mobility even in the amorphous phases.

Recently, Ye et al. proposed a mixed anion compound, zinc oxynitride $\left(\mathrm{ZnO}_{x} \mathrm{~N}_{y}\right)$, as a novel amorphous semiconductor. ${ }^{3}$ In contrast to the conventional AOSs, amorphous $\mathrm{ZnO}_{x} \mathrm{~N}_{y}$ is an alloy of an oxide ( $\mathrm{ZnO}$, wurtzite) and a nitride $\left(\mathrm{Zn}_{3} \mathrm{~N}_{2}\right.$, anti-bixbyite) that have the same cation. A remarkable feature of amorphous $\mathrm{ZnO}_{x} \mathrm{~N}_{y}$ is its high electron Hall mobility, over $100 \mathrm{~cm}^{2} \mathrm{~V}^{-1} \mathrm{~s}^{-1,4-6}$ which is comparable with the highest reported values for AOSs. ${ }^{7,8}$ However, more recent studies using transmission electron microscopy (TEM) and electron diffraction revealed that these "amorphous" $\mathrm{ZnO}_{x} \mathrm{~N}_{y}$ thin films contained nanocrystals of $\mathrm{ZnO}$ and $\mathrm{Zn}_{3} \mathrm{~N}_{2}$, which would reduce their mobility through grain boundary scattering. Conversely, the mobility of amorphous $\mathrm{ZnO}_{x} \mathrm{~N}_{y}$ thin films can be further enhanced by reducing the nanocrystals.

\footnotetext{
${ }^{\text {a) }}$ Author to whom correspondence should be addressed. Electronic mail: hirose@chem.s.u-tokyo.ac.jp
}

To suppress the formation of nanocrystals in this paper, we focused on the deposition process. In the previous studies, ${ }^{3-6} \mathrm{ZnO}_{x} \mathrm{~N}_{y}$ thin films were fabricated by reactive sputtering. However, sputtering frequently causes unintentional substrate heating ${ }^{9,10}$ and collisions of high-energy particles with the film surface during deposition, which would induce crystallization of the film. ${ }^{11,12}$ In this study, we fabricated $\mathrm{ZnO}_{x} \mathrm{~N}_{y}$ thin films by using nitrogen-plasma-assisted pulsed laser deposition (NPA-PLD), in which the above-mentioned "heating" effects are less significant because of lower averaged power of the ablation laser (typically less than $1 \mathrm{~W}$ ). The $\mathrm{ZnO}_{x} \mathrm{~N}_{y}$ thin films grown under optimized conditions exhibited very flat surfaces owing to the suppression of nanocrystals and twice as high electron Hall mobility, $240 \mathrm{~cm}^{2} \mathrm{~V}^{-1} \mathrm{~s}^{-1}$, as that of the reported sputter-deposited films.

The $\mathrm{ZnO}_{x} \mathrm{~N}_{y}$ thin films were grown by NPA-PLD ${ }^{13-16}$ on alkali-free glass substrates (Corning, EagleXG) without heating the substrate. The substrate temperature during deposition was $<50^{\circ} \mathrm{C}$, measured using a nonreversible temperature indicator (Nichiyu Giken Kogyo, Thermo Label). A ceramic $\mathrm{ZnO}$ target $(99.999 \%)$ was ablated by a $\mathrm{KrF}$ excimer laser with a target-to-substrate distance of $50 \mathrm{~mm}$. The laser energy fluence was set to $\sim 0.2 \mathrm{~J} \mathrm{~cm}^{-2}$ per pulse, nearly the ablation threshold, to minimize the kinetic energy of the ablated species. ${ }^{17}$ Indeed, the films grown at a high laser energy fluence tended to crystallize. The typical deposition rate and thickness of the films $t$ were $0.4-0.7 \mathrm{~nm} / \mathrm{min}$ and $\sim 30 \mathrm{~nm}$, respectively. Nitrogen radicals were supplied from an electron cyclotron resonance (ECR) plasma source (Tectra, Gen2 
Atomsource). The partial pressure of $\mathrm{N}_{2}$ gas introduced into the growth chamber was fixed at $5 \times 10^{-5}$ Torr, and the amount of nitrogen radicals was controlled by the input current of the ECR source $\left(I_{\mathrm{ECR}}\right)$. The background pressure of the growth chamber was lower than $3 \times 10^{-9}$ Torr.

The crystal structure and surface morphology of the $\mathrm{ZnO}_{x} \mathrm{~N}_{y}$ films were evaluated by X-ray diffraction (XRD; Bruker AXS, D8 DISCOVER with GADDS) and atomic force microscopy (AFM; SII, SPI4000 with SPA400), respectively. The chemical compositions of the films were determined by elastic recoil detection analysis (ERDA) for $\mathrm{N}$ and $\mathrm{O}$ as well as the Rutherford backscattering spectrometry (RBS) for $\mathrm{Zn}$ with a $38.4 \mathrm{MeV}{ }^{35} \mathrm{Cl}$ beam generated by a 5-MV tandem accelerator (Micro Analysis Laboratory, The University of Tokyo [MALT]). ${ }^{18}$ To reduce the background oxygen from the substrate, $\mathrm{ZnO}_{x} \mathrm{~N}_{y}$ films deposited on $\mathrm{Si}$ substrate were used for the ERDA measurement. The ratio of effective solid angles of the detectors for ERDA and RBS measurements was calibrated using a stoichiometric $\mathrm{ZnO}$ thin film. The experimental errors in the $x$ and $y$ values were determined by statistical errors, and were less than $\pm 5 \%$ under a typical condition (total dose of $\sim 2 \times 10^{12}$ ions). The optical transmittance $T$ and reflectance $R$ of the films were measured by using a UV/visible/near-infrared spectrophotometer (JASCO, V-670). The absorption coefficient $\alpha$ was calculated by $T /(1-R)=\exp (-\alpha \cdot t)$. The electrical resistivity $(\rho)$, carrier density $\left(N_{\mathrm{e}}\right)$, and Hall mobility $(\mu)$ of the films were measured at room temperature using the six-probe method with the standard Hall bar geometry.

Figure 1 shows the chemical compositions of the $\mathrm{ZnO}_{x} \mathrm{~N}_{y}$ thin films deposited with various $I_{\mathrm{ECR}}$. For the $\mathrm{ZnO}_{x} \mathrm{~N}_{y}$ films grown with $I_{\mathrm{ECR}} \lesssim 15 \mathrm{~mA}$, the nitrogen amount $y$ monotonically increased with increasing $I_{\mathrm{ECR}}$. The nominal charges of $\mathrm{Zn}$, evaluated as $2 x+3 y$, in these films were smaller than +2 , suggesting the existence of metal $\mathrm{Zn}$ as an impurity phase. However, for $I_{\mathrm{ECR}} \geq \sim 15 \mathrm{~mA}, y$ is saturated and the chemical composition was almost constant as $\mathrm{ZnO}_{0.31} \mathrm{~N}_{0.46}$. The nominal charges of $\mathrm{Zn}$ calculated from this composition was nearly +2 , indicating the disappearance of

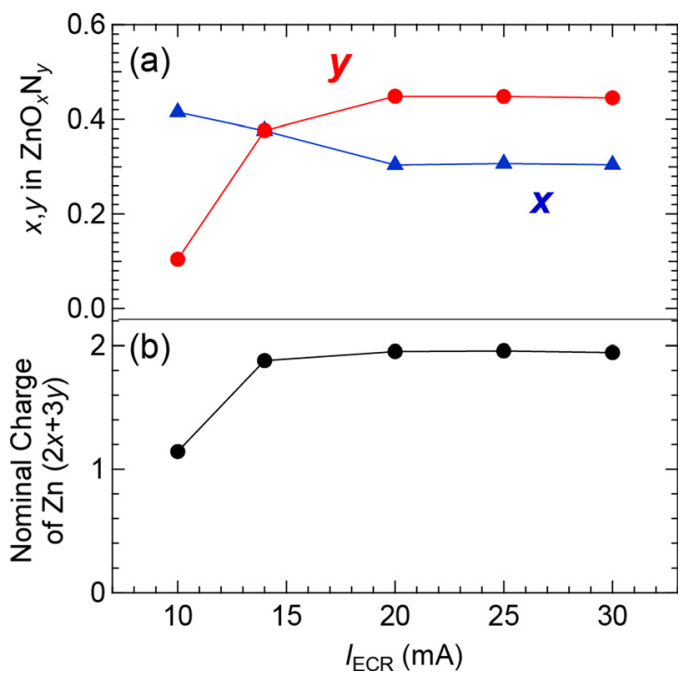

FIG. 1. (a) Chemical compositions of the $\mathrm{ZnO}_{x} \mathrm{~N}_{y}$ thin films fabricated with various $I_{\mathrm{ECR}}$. (b) Nominal charge of $\mathrm{Zn}$ in the $\mathrm{ZnO}_{x} \mathrm{~N}_{y}$ thin films $(2 x+3 y)$ calculated from the $x$ and $y$ values in (a) plotted against $I_{\mathrm{ECR}}$.

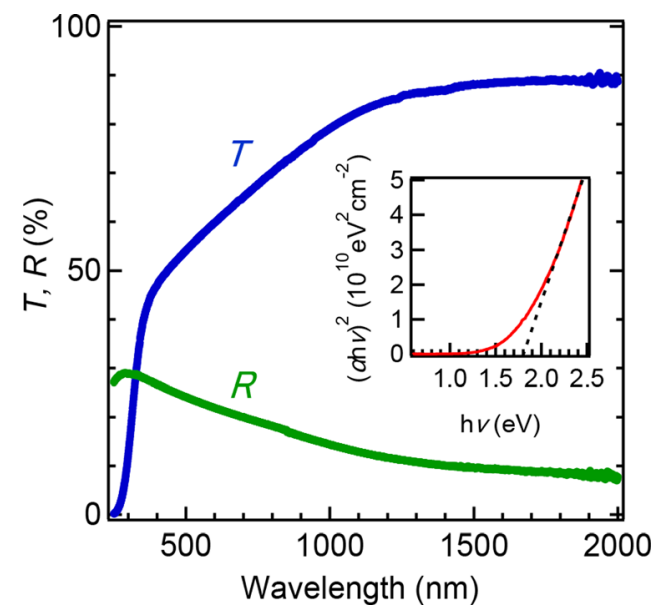

FIG. 2. Optical transmittance $(T)$ and reflectance $(R)$ spectra of the $\mathrm{ZnO}_{0.31} \mathrm{~N}_{0.46}$ thin film fabricated with $I_{\mathrm{ECR}}=30 \mathrm{~mA}$. Inset shows the $(\alpha h v)^{2}-h v$ plot (direct transition model) of the film.

metal $\mathrm{Zn}$. Hereafter, we focused on the films grown with $I_{\mathrm{ECR}} \geq \sim 15 \mathrm{~mA}$ to prevent the presence of metal $\mathrm{Zn}$ from influencing the physical properties. Figure 2 shows the optical properties of the $\mathrm{ZnO}_{0.31} \mathrm{~N}_{0.46}$ thin film fabricated with $I_{\mathrm{ECR}}=30 \mathrm{~mA}$. Using the Tauc plot assuming a direct transition- $(\alpha h v)^{2}$ vs. $h v$, where $h$ and $v$ represent the Plank's constant and the frequency of incident light, respectively-we evaluated the absorption edge of the film to be $\sim 1.8 \mathrm{eV}$. This value is very different from those of $\mathrm{ZnO}$ and $\mathrm{Zn}_{3} \mathrm{~N}_{2}$, indicating that the film consisted of a single-phase $\mathrm{ZnO}_{x} \mathrm{~N}_{y}$, not a mixture of $\mathrm{ZnO}$ and $\mathrm{Zn}_{3} \mathrm{~N}_{2}$. Although $\mathrm{Zn}_{3} \mathrm{~N}_{2}$ thin films containing interstitial nitrogen may show a similar optical gap, ${ }^{19,20}$ this possibility can be eliminated from the results of XRD and Hall measurements, as described below.

Figure 3 shows $\theta-2 \theta$ XRD patterns of the $\mathrm{ZnO}_{x} \mathrm{~N}_{y}$ thin films fabricated with various $I_{\mathrm{ECR}}$. All of the films exhibited featureless patterns without any diffraction peaks. Despite the similarity in the XRD patterns, these $\mathrm{ZnO}_{x} \mathrm{~N}_{y}$ thin films had very different surface morphologies that strongly depended on $I_{\mathrm{ECR}}$, as follows. The $\mathrm{ZnO}_{x} \mathrm{~N}_{y}$ films fabricated with low $I_{\mathrm{ECR}}$ exhibited a grain-like surface structure (Figs.

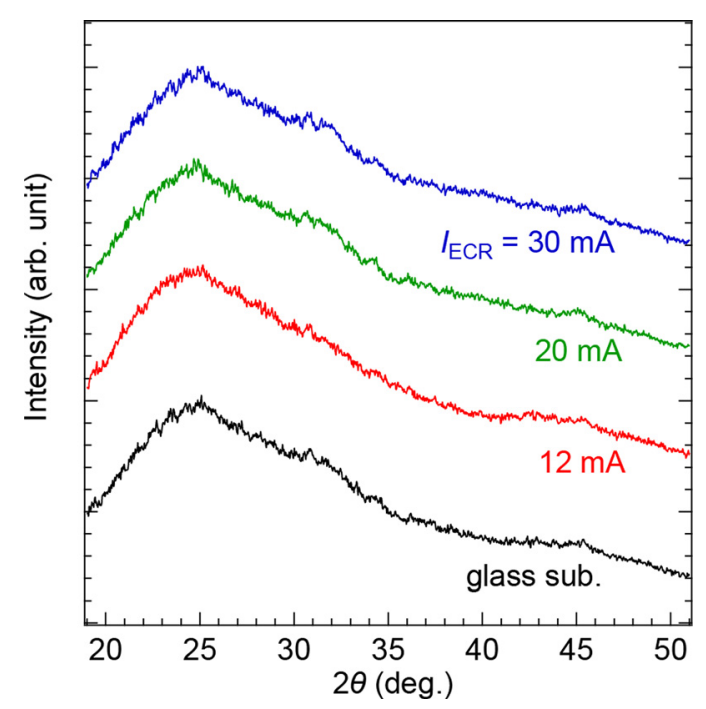

FIG. 3. $\theta-2 \theta$ XRD patterns of the $\mathrm{ZnO}_{x} \mathrm{~N}_{y}$ thin films fabricated with various $I_{\mathrm{ECR}}$. 


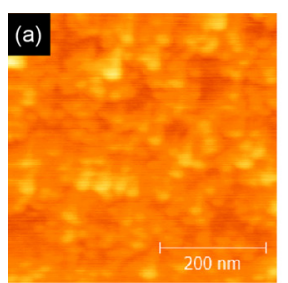

$I_{\mathrm{ECR}}=15 \mathrm{~mA}$

$R_{\mathrm{rms}}=0.35 \mathrm{~nm}$

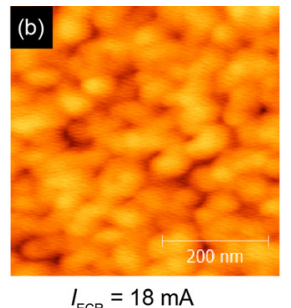

$I_{\mathrm{ECR}}=18 \mathrm{~mA}$
$R_{\mathrm{rms}}=0.48 \mathrm{~nm}$

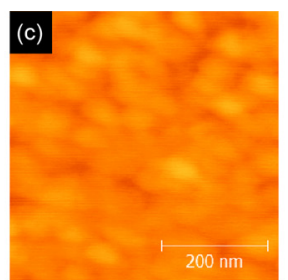

$I_{\mathrm{ECR}}=25 \mathrm{~mA}$

$R_{\mathrm{rms}}=0.21 \mathrm{~nm}$

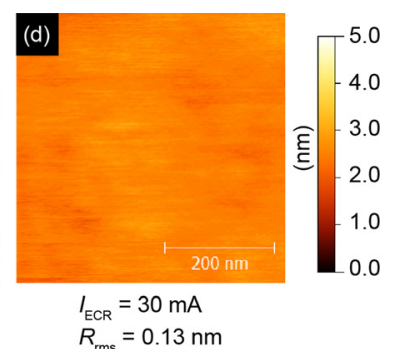

FIG. 4. AFM images $\left(0.5 \times 0.5 \mu \mathrm{m}^{2}\right)$ of the $\mathrm{ZnO}_{x} \mathrm{~N}_{y}$ thin films fabricated with $I_{\mathrm{ECR}}=$ (a) $15 \mathrm{~mA}$, (b) $18 \mathrm{~mA}$, (c) $25 \mathrm{~mA}$, and (d) $30 \mathrm{~mA}$. Also shown are $R_{\text {rms }}$ values calculated from the AFM images. 4(a) and 4(b)). Because a similar grain-like structure appeared for the sputter-deposited films containing nanocrystals, ${ }^{5}$ we believe that these structures originated from nanocrystals inside the films. In contrast, the $\mathrm{ZnO}_{x} \mathrm{~N}_{y}$ films fabricated with high $I_{\mathrm{ECR}}$ showed a smoother surface without a grain-like structure, and the root-mean-squared surface roughness $\left(R_{\text {rms }}\right)$ reached the same level as the glass substrates, $\sim 0.2 \mathrm{~nm}$ (Fig. 4(d)). Because such an extremely flat surface is a characteristic feature of amorphous oxide thin films grown by PLD, ${ }^{21,22}$ we reasonably conclude that the decrease of surface roughness comes from the reduction of nanocrystals. For simplicity, we hereafter classified our films into two groups based on $R_{\text {rms }}$ : films containing nanocrystals $\left(R_{\mathrm{rms}} \geq 0.3 \mathrm{~nm}\right)$ and supposedly "completely" amorphous films without nanocrystals $\left(R_{\mathrm{rms}}<0.3 \mathrm{~nm}\right)$.

Figures 5(a)-5(c) plot the $N_{\mathrm{e}}, \mu$, and $R_{\mathrm{rms}}$ of the $\mathrm{ZnO}_{x} \mathrm{~N}_{y}$ thin films as functions of $I_{\mathrm{ECR}}$, respectively. As shown in Figs. 5(a) and 5(b), as $I_{\mathrm{ECR}}$ increased, $N_{\mathrm{e}}$ decreased, and $\mu$ increased. Notably, the $\mu$ of the $\mathrm{ZnO}_{x} \mathrm{~N}_{y}$ thin films fabricated with $I_{\mathrm{ECR}} \geq 25 \mathrm{~mA}$ exceeded $200 \mathrm{~cm}^{2} \mathrm{~V}^{-1} \mathrm{~s}^{-1}$, which is even higher than those of the polycrystalline $\mathrm{ZnO}$ (Ref. 23) and $\mathrm{Zn}_{3} \mathrm{~N}_{2}$ (Refs. 19 and 20) thin films. The carrier (electron) source of the $\mathrm{ZnO}_{x} \mathrm{~N}_{y}$ thin films are probably anion vacancies as in the cases of AOSs. ${ }^{21}$ In order to verify this assignment, a small amount of oxygen gas (partial pressure $P_{\mathrm{O} 2} \leq 5$ $\times 10^{-6}$ Torr) was introduced during the deposition with a constant $I_{\mathrm{ECR}}=30 \mathrm{~mA}$. As shown in Fig. 5(d), $N_{\mathrm{e}}$ monotonically decreased with an increasing $P_{\mathrm{O} 2}$, supporting that anion vacancies are the dominant source of carrier electrons. It was also observed that the introduction of oxygen gas induces an increase of $R_{\mathrm{rms}}$ and a reduction of $\mu$ (Figs. 5(e) and 5(f)), while the change of anion composition was smaller than the experimental error in compositional analysis. Figure $5(\mathrm{~g})$ summarizes $\mu-R_{\text {rms }}$ relation of the $\mathrm{ZnO}_{x} \mathrm{~N}_{y}$ thin films. Although the plots are scattered probably due to the influence of $N_{\mathrm{e}}$, as discussed later, they can be obviously classified into two groups below and above a critical $R_{\mathrm{rms}}$ of $\sim 0.3 \mathrm{~nm}$ : All of the "completely" amorphous films showed $\mu$ higher than $170 \mathrm{~cm}^{2} \mathrm{~V}^{-1} \mathrm{~s}^{-1}$, while $\mu$ in the other films were at most $\sim 160 \mathrm{~cm}^{2} \mathrm{~V}^{-1} \mathrm{~s}^{-1}$ and were in almost the same range as the reported data for the sputter-deposited $\mathrm{ZnO}_{x} \mathrm{~N}_{y}$ thin films ${ }^{3-5}$ (shaded area in Fig. 5(g)). This difference in $\mu$ between these two groups supports the scenario that the increased $\mu$ is attributable to a reduction in grain-boundary scattering.

Another possible factor for enhancement of $\mu$ is the carrier density $N_{\mathrm{e}}$. Figure 6 showed the relation between $\mu$ and $N_{\mathrm{e}}$ of the PLD-grown $\mathrm{ZnO}_{x} \mathrm{~N}_{y}$ thin films together with the literature values for sputter-deposited ones. ${ }^{3,5}$ The PLD-grown films containing nanocrystals (triangles) showed a peak $\mu$ at
$N_{\mathrm{e}}$ of $\sim 1 \times 10^{19} \mathrm{~cm}^{-3}$, indicating a change in the dominant carrier transport mechanism at this critical $N_{\mathrm{e}}$ as reported in amorphous oxide semiconductors. ${ }^{21,24}$ A similar peak of $\mu$ was observed for the sputter-deposited $\mathrm{ZnO}_{x} \mathrm{~N}_{y}$ although we have to take into account the influence of the chemical compositions on $\mu:{ }^{4}$ the PLD-grown films have a constant anion composition of $\mathrm{N} /(\mathrm{N}+\mathrm{O}) \sim 0.6$ whereas the sputterdeposited films showed a wide variety of chemical composition $^{5}$ (Fig. 6, inset). We also admit that the $N_{\mathrm{e}}$ values of the "completely" amorphous $\mathrm{ZnO}_{x} \mathrm{~N}_{y}$ thin films (circles) are close to the critical $N_{\mathrm{e}}\left(\sim 1 \times 10^{19} \mathrm{~cm}^{-3}\right)$, indicating that the closeness of $N_{\mathrm{e}}$ to the critical value is one of the origins of their very high $\mu$. On the other hand, the shape of the $\mu-N_{\mathrm{e}}$ curve strongly suggests the presence of another origin for the
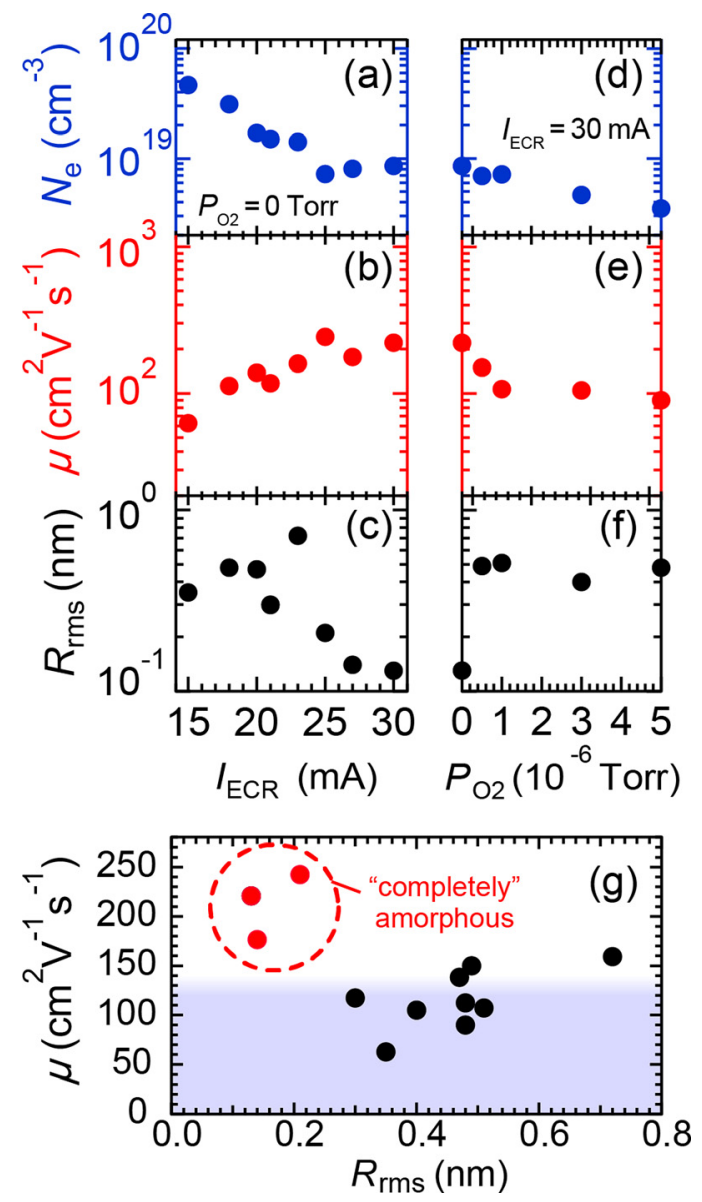

FIG. 5. ((a), (d)) Carrier density $N_{\mathrm{e}}$, ((b), (e)) Hall mobility $\mu$, and ((c), (f)) surface roughness $R_{\mathrm{rms}}$ of $\mathrm{ZnO}_{x} \mathrm{~N}_{y}$ thin films. ((a)-(c)) Properties of the films fabricated with various $I_{\mathrm{ECR}}$ without $\mathrm{O}_{2}$ introduction and ((d)-(f)) those with constant $I_{\mathrm{ECR}}=30 \mathrm{~mA}$ and various $P_{\mathrm{O} 2} . R_{\mathrm{rms}}$ values were calculated from the AFM images over $0.5 \times 0.5 \mu \mathrm{m}^{2}$. (g) Hall mobility of the $\mathrm{ZnO}_{x} \mathrm{~N}_{y}$ thin films plotted against $R_{\text {rms }}$. Shaded area represents the mobility range reported for sputter-deposited $\mathrm{ZnO}_{x} \mathrm{~N}_{y}$ thin films. ${ }^{3-5}$ 


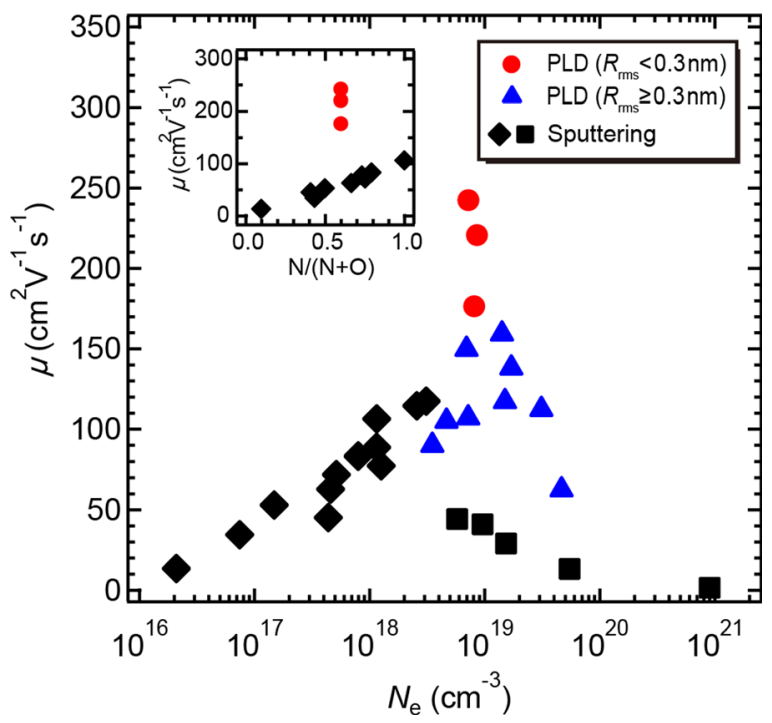

FIG. 6. Hall mobility of the $\mathrm{ZnO}_{x} \mathrm{~N}_{y}$ thin films plotted against carrier density. Circles and triangles are values from the PLD-grown films with $R_{\text {rms }}<0.3 \mathrm{~nm}$ ("completely" amorphous) and from those with $R_{\mathrm{rms}} \geq 0.3 \mathrm{~nm}$ (containing nanocrystals), respectively. The squares (Ref. 3) and diamonds (Ref. 5) are values for reported sputter-deposited films. Inset shows the mobilities of the "completely amorphous" films grown by PLD and those of the sputter-deposited films (Ref. 5) as a function of the anion composition.

mobility enhancement in these films: It is generally known that the $\mu-N_{\mathrm{e}}$ curves of oxide semiconductors have a broad peak at the critical $N_{\mathrm{e}}$. Indeed, the $\mu-N_{\mathrm{e}}$ curves of the $\mathrm{ZnO}_{x} \mathrm{~N}_{y}$ films containing nanocrystals show a broad peak. In contrast, $\mu$ of the "completely" amorphous $\mathrm{ZnO}_{x} \mathrm{~N}_{y}$ thin films shows a very sharp peak, which is significantly distinguished from the broad peak feature described above. Therefore, we believe that the substantial enhancement in $\mu$ from $\sim 160 \mathrm{~cm}^{2}$ $\mathrm{V}^{-1} \mathrm{~s}^{-1}$ to $\sim 250 \mathrm{~cm}^{2} \mathrm{~V}^{-1} \mathrm{~s}^{-1}$ at the critical $N_{\mathrm{e}}$ in the "completely" amorphous $\mathrm{ZnO}_{x} \mathrm{~N}_{y}$ films is attributable to a reduction of nanocrystals.

In summary, we fabricated the "completely" amorphous $\mathrm{ZnO}_{x} \mathrm{~N}_{y}$ thin films on glass substrates by NPA-PLD. The closeness of $N_{\mathrm{e}}$ to a critical value and the suppressed formation of nanocrystals dramatically enhanced $\mu$ in the $\mathrm{ZnO}_{x} \mathrm{~N}_{y}$ thin films up to $>200 \mathrm{~cm}^{2} \mathrm{~V}^{-1} \mathrm{~s}^{-1}$, which is twice as high as those of the sputter-deposited $\mathrm{ZnO}_{x} \mathrm{~N}_{y}$ thin films. These results demonstrate that less-energetic deposition is the key to fabricating amorphous $\mathrm{ZnO}_{x} \mathrm{~N}_{y}$ thin films with a very high $\mu$. It is also suggested that a high $\mu$ around $200 \mathrm{~cm}^{2} \mathrm{~V}^{-1} \mathrm{~s}^{-1}$ can be achieved even in sputter-deposited $\mathrm{ZnO}_{x} \mathrm{~N}_{y}$ thin films by preventing the formation of nanocrystals. Facing-target sputtering $^{12}$ and/or heavier noble gas sputtering ( $\mathrm{Kr}$ or $\mathrm{Xe}$ ) might be effective in preventing the unintentional substrate heating and/or the formation of high-energy charged particles.

We thank Professor Hiroyuki Matsuzaki of The University of Tokyo for his assistance in ERDA measurements. This study was financially supported by CREST, Japan Science and Technology Agency (JST) and Tokyo Ohka Foundation for The Promotion of Science and Technology.

${ }^{1}$ K. Nomura, H. Ohta, A. Takagi, T. Kamiya, M. Hirano, and H. Hosono, Nature 432, 488 (2004).

${ }^{2}$ T. Kamiya, K. Nomura, and H. Hosono, Sci. Technol. Adv. Mater. 11, 044305 (2010).

${ }^{3}$ Y. Ye, R. Lim, and J. M. White, J. Appl. Phys. 106, 074512 (2009).

${ }^{4}$ E. Lee, A. Benayad, T. Shin, H. Lee, D.-S. Ko, T. S. Kim, K. S. Son, M. Ryu, S. Jeon, and G.-S. Park, Sci. Rep. 4, 4948 (2014).

${ }^{5}$ H.-S. Kim, S. H. Jeon, J. S. Park, T. S. Kim, K. S. Son, J.-B. Seon, S.-J. Seo, S.-J. Kim, E. Lee, J. G. Chung, H. Lee, S. Han, M. Ryu, S. Y. Lee, and K. Kim, Sci. Rep. 3, 1459 (2013).

${ }^{6}$ E. Lee, T. Kim, A. Benayad, J. Hur, G.-S. Park, and S. Jeon, Sci. Rep. 6, 23940 (2016).

${ }^{7}$ E. Fortunato, P. Barquinha, A. Pimentel, L. Pereira, G. Goncalves, and R. Martins, Phys. Status Solidi RRL 1, R34 (2007).

${ }^{8}$ M.-G. Kim, H. S. Kim, Y.-G. Ha, J. He, M. G. Kanatzidis, A. Facchetti, and T. J. Marks, J. Am. Chem. Soc. 132, 10352 (2010).

${ }^{9}$ V. I. Shapovalov, A. E. Komlev, A. S. Bondarenko, P. B. Baykov, and V. V. Karzin, Phys. Lett. A 380, 882 (2016).

${ }^{10}$ J. A. Thornton, Thin Solid Films 54, 23 (1978).

${ }^{11}$ I. Brodie, L. T. Lamont, Jr., and D. O. Myers, J. Vac. Sci. Technol. 6, 124 (1969).

${ }^{12}$ K. Ellmer and T. Welzel, J. Mater. Res. 27, 765 (2012).

${ }^{13}$ D. Oka, Y. Hirose, H. Kamisaka, T. Fukumura, K. Sasa, S. Ishii, H. Matsuzaki, Y. Sato, Y. Ikuhara, and T. Hasegawa, Sci. Rep. 4, 4987 (2014).

${ }^{14}$ D. Oka, Y. Hirose, T. Fukumura, and T. Hasegawa, Cryst. Growth Des. 14, 87 (2014).

${ }^{15}$ A. Suzuki, Y. Hirose, D. Oka, S. Nakao, T. Fukumura, S. Ishii, K. Sasa, H. Matsuzaki, and T. Hasegawa, Chem. Mater. 26, 976 (2014).

${ }^{16}$ J. Takahashi, Y. Hirose, D. Oka, S. Nakao, C. Yang, T. Fukumura, I. Harayama, D. Sekiba, and T. Hasegawa, Appl. Phys. Lett. 107, 231906 (2015).

${ }^{17}$ R. E. Leuchtner, Appl. Surf. Sci. 127-129, 626 (1998).

${ }^{18}$ I. Harayama, K. Nagashima, Y. Hirose, H. Matsuzaki, and D. Sekiba, Nucl. Instrum. Methods Phys. Res., Sect. B 384, 61 (2016).

${ }^{19}$ X. Cao, A. Sato, Y. Ninomiya, and N. Yamada, J. Phys. Chem. C 119, 5327 (2015).

${ }^{20}$ T. Suda and K. Kakishita, J. Appl. Phys. 99, 076101 (2006).

${ }^{21}$ K. Nomura, A. Takagi, T. Kamiya, H. Ohta, M. Hirano, and H. Hosono, Jpn. J. Appl. Phys., Part 1 45, 4303 (2006).

${ }^{22}$ S. Nakao, Y. Hirose, T. Fukumura, and T. Hasegawa, Jpn. J. Appl. Phys., Part 1 53, 05FX04 (2014).

${ }^{23}$ K. Ellmer, J. Phys. D: Appl. Phys. 34, 3097 (2001).

${ }^{24}$ A. J. Leenheer, J. D. Perkins, M. F. A. M. van Hest, J. J. Berry, R. P. O’Hayre, and D. S. Ginley, Phys. Rev. B 77, 115215 (2008). 